\title{
Comparison of Two Irradiated Metallic Fuels by Electron Probe Micro-analysis
}

Philipp Poeml ${ }^{1}$, Karen Wright ${ }^{2}$, Hirokazu Ohta ${ }^{3}$, Luca Capriotti ${ }^{2}$ and Jason Harp ${ }^{4}$

${ }^{1}$ European Commission - Joint Research Centre, Eggenstein-Leopoldshafen, Baden-Wurttemberg, Germany, ${ }^{2}$ Idaho National Laboratory, Idaho Falls, Idaho, United States, ${ }^{3}$ Central Research Institute of Electric Power Industry, Yokosuka-shi, Kanagawa, Japan, ${ }^{4}$ Oak Ridge National Laboratory, Oak Ridge, Tennessee, United States

One of the barriers to nuclear waste disposal is the presence of long-lived minor actinides (Np, Am, Cm) that result from the irradiation of commercial light water reactor oxide fuel. One strategy to address this issue is to separate the minor actinide (MA) elements from the spent fuel, incorporate them into $\mathrm{U}-\mathrm{Pu}-\mathrm{Zr}$ metallic fuels, and irradiate them under a fast neutron spectrum, thereby transmuting them into shorterlived, less toxic nuclides. $71 \mathrm{U}-19 \mathrm{Pu}-10 \mathrm{Zr}$ (where the prefix numbers indicate weight percent) nuclear fuel is well-studied $[1,2]$. Some of the post-irradiation observations with this fuel include: 1) elemental redistribution, where $\mathrm{Zr}$ moves toward the center and $\mathrm{U}$ moves toward the cladding [1]; 2) rare element$\mathrm{Pd} / \mathrm{Rh}$ rich second phase precipitation [3]; 3) extensive fuel cladding chemical interaction [1]. However, few studies have been published involving MA addition to metallic nuclear fuels. Two recent experiments, the FUTURIX-FTA, and the METAPHIX, seek to remedy that deficit. The FUTURIX-FTA experiment irradiated 34.1U-28.3Pu-3.8Am-2.1Np-31.7Zr fuel to a burnup of 9.5\% fissions per initial metal atom (FIMA) in the Phénix fast reactor, while the METAPHIX-2 experiment irradiated 66.3U-19.35Pu-2.97Np$1.45 \mathrm{Am}-0.32 \mathrm{Cm}-8.97 \mathrm{Zr}$ fuel to $7 \%$ FIMA in the same reactor [4]. While these fuels have similar MA contents, their U-Pu-Zr contents vary considerably. The FUTURIX-FTA experiment sought to increase burning, therefore increased the fuel's ${ }^{239} \mathrm{Pu}$ content. To compensate for the lowered solidus, the uranium content was decreased, and the zirconium content was increased. Because of these compositional differences, it is anticipated that fuels will behave very differently, particularly with regard to fuelcladding chemical interaction. To that end, a Cameca SX100R radiologically shielded electron probe microanalyzer (EPMA) was used to analyze both fuels to compare elemental redistribution patterns, second phase formation, and fuel-cladding chemical interaction. In this contribution we are going to present the results of the comparison of the two fuels.

\section{References}

[1] G.L. Hofman et al., Progress in Nuclear Energy 31, (1997), 83-110.

[2] Y.S. Kim et al., Journal of Nuclear Materials 359, (2006), 17-28.

[3] S. Brémier, et al., Journal of Nuclear Materials 480, (2016), 109-119

[4] L. Capriotti et al., Progress in Nuclear Energy 94, (2017), 194-201. 